book cataloguing and acquisition suggests to the publishers that they should take this more seriously.

F. W. Matthews

\author{
Central Technical Information Unit \\ Imperial Chemical Industries Ltd. \\ Imperial Chemical House \\ Millbank \\ London S.W.1 \\ England
}

Physics of $p-n$ junctions and semiconductor devices. Edited by S. M. RYVKIN and YU V. SHMARTSEV. Pp. ix +366 . New York: Plenum, Press, 1971 Price $\$ 44.80$.

The title may seem vague and this is perhaps in keeping with the book. There is no introduction or other indication of how the book came to be assembled. It was published in Russian in 1969 for the A. F. loffe Physicotechnical Institute of the Academy of Sciences of the USSR but there is no indication whether it was associated with a conference or whether, slightly late, it commemorated the 50th anniversary of the loffe Institute.

The book consists of 68 articles on topics from $n-p-n-p-n-p$ silicon device structures to strain effects in polycrystalline films of indium antimonide and gallium antimonide. The articles seem almost randomly distributed and, without even an author index, one has to plough through the list of contents to find a particular article or topic.

There is no main theme but half the papers could be classified as concerning either multilayer silicon structures (thyristors etc.), optoelectronic properties of $p-n$ junctions in III-V compounds, semiconductor lasers, thin-film properties, or pressure effects in semiconductors. Partly because of the delay in publishing, some of the material or similar work by other authors has appeared in journals elsewhere. However, some of the articles are of interest and do add to some extent to the state of knowledge. For example, though work on thermally stimulated currents in gallium phosphide junctions has been reported elsewhere, more reliable methods of analysis are given in an article in the book.
It is not clear for whom the book is written, as it serves as neither an introduction, authoritative treatise or bibliography concerning $p-n$ junctions and devices, nor as a compendium of recent work on one particular aspect. The final crunch is the cost of the 366 page book, which is only matched by the number of different contributing (158).

K. H. NICHOLAS

Mullard Research Laboratories

Redhill

Surrey

England

\section{Structural characteristics of} materials. Edited by H.M. Finniston. Pp. $x+318$. Amsterdam: Elsevier, 1971. Price f. 6900 (ca. $\$ 19.25$ )

This book consists of six independent chapters entitled: Crystallography of Materials, H. Lipson and S. G. Lipson; Defect Structures, A. G. Crocker; Mechanical Twinning, D. Hull and E. Roberts; Martensitic Structures, W. S. Owen and F. J. Schoen; Development of Microstructure, R. B. Nicholson and G. J. Davies; Structural Defects in Nonstoichiometric Compounds, B. T. M. Willis and J. Williams. The whole text is plentifully illustrated with optical and electron micrographs. Chapters 1 and 2 are introductory in nature, but each of the others provides an up-to-date, well documented account of its field that will be profitably read by the interested expert. It appears that a genuine insight has been achieved into the atom movements involved in mechanical twinning. However the same cannot be said of martensite formation. This is an inherently more complex phenomenon than twinning, and theories are still getting confounded by the emergence of fresh facts concerning the relaxation of constraints. Thermodynamics remains the key to understanding the development of microstructure, but further progress seems to depend increasingly on the recognition of metastable transition phases that ease the reaction path towards equilibrium. The final chapter essentially constitutes a succint mathematical appendix to the first.
The various articles present a valuable interim picture of a lively research area, but they hardly support the claim expressed in the blurb that 'there has been a great deal of consolidation of experimental results and a leavening of the multiplicity of theories surrounding new developments'. I certainly missed a general covering chapter that would have expanded the blurb and explained the choice of topics, in particular their virtual restriction to metallurgical systems despite the book's very broad title

M. A. JASWON

\author{
Mathematics Department \\ The City University \\ St. John Street \\ London E. C. 1
}

The physics of opto-electronic material. Edited by W.A. Albers JR. Pp.xV + 281. New York: Plenum Press, 1972. Price $\$ 18.48$.

This book contains selected papers on opto-electronic materials taken from a Symposium held at General Motors Research Laboratories on 4-6 October 1970 , and is the first in a G. M. Symposia Series.

Topics include a review of non-linear optics, simple models accounting for the optical properties of semi-conductors and insulators.

Of marginal interest to crystallographers are papers on single-crystal ferroelectrics, the optics of solid state phase transformations and the light-scattering properties of nematic liquid crystals.

The papers selected provide an effective cover of both the theme of the conference and recent research irito new electro-optic materials and their applications in such fields as laser beam steering and modulation. This book is aimed primarily at the physicist researching into electro-optic materials and systems.

D. GOODWIN

Department of Physics

University of York

Heslington

York YO1 5DD

England 